\title{
Social facilitation of drinking of a partially satiated duckling
}

\author{
DAVID A. CLAYTON \\ The University, Leicester LE1 7RH, England
}

\begin{abstract}
Water-deprived and nondeprived ducklings were reintroduced to a flock companion which had been allowed to partially satiate itself after $3 \mathrm{~h}$ of water deprivation. The drinking and sieving behavior of the partially satiated "reactor" bird was immediately increased above that of similar birds left on their own. However, whether or not the introduced "actor" ducklings were deprived had no consequences for the drinking response of the reactor above that obtained by their introduction. The number of companions introduced also failed to have any effect other than that obtained by their introduction. The increase in sieving was greater when deprived, rather than nondeprived, actors were introduced. These results were discussed in relation to the motivational aspects of sieving behavior and the mechanism of social facilitation.
\end{abstract}

A method commonly employed to demonstrate social facilitation is to compare the behavior of isolates with that of individuals in simultaneously coacting pairs or groups (May \& Dorr, 1968; Platt \& James, 1966; Tolman, 1964; Turner, 1964). A refinement is to look at the behavior of the individual with companions of different motivational states (Tolman, 1968, 1969; Wilson, 1968). An alternative strategy is to allow an isolate, the "reactor," to complete the task before it and then introduce the social companion(s) or "actor(s)" (Bayer, 1928; Beck, 1931; Ross \& Ross, 1949; Simmel, 1962). In this situation, the comparison is between what the reactor animal would have done if left on its own and what it did when the actor companion(s) was added. Here too, the behavior of the reactor may varying according to the motivational state of the introduced companions.

While social facilitation of the same activity (pecking in chicks, for example) can be demonstrated by both these methods, the mechanisms by which the facilitated response is produced need not be the same. Social facilitation was originally a descriptive term, but several authors have produced casual definitions of the term which Tolman (1968) summarized in four general categories. These are the reflexive, motivational, perceptual, and disinhibitory mechanisms. A fifth, the drive theory of social facilitation, was proposed by Zajonc (1965).

This article is based on a thesis submitted to the Department of Psychology, Leicester University, England, in partial fulfillment of the requirements of the $\mathrm{PhD}$ degree. The author would like to express his gratitude to the Science Research Council for financing the project, to Dr. U. Weidmann for so ably supervising the research, and to Professor R. J. Andrew and Dr. P. J. B. Slater for their comments on an earlier version of this manuscript. The author's present address: School of Biological Sciences, University of Sussex, Falmer, Brighton, England.
In a study of the mechanism of social facilitation of the duckling's drinking response in simultaneously coacting groups (Clayton, 1972, 1976), it was found that the individual's drinking response was only facilitated in the presence of similarly 3-h waterdeprived birds. That similarity between actor and reactor in motivational state was a prerequisite for social facilitation of drinking was given further support by the fact that 3-h water-deprived ducklings were not effective in inducing nondeprived companions to drink. Instead of drinking, they engaged in sieving, an activity in which water is filtered through the bill membranes. Conversely, in these simultaneously coacting groups, nondeprived ducklings were not effective in inducing deprived birds to sieve instead of drink and only produced facilitation of drinking when their presence prevented an otherwise isolated bird from becoming distressed. This, it should be noted, is brought about by the disinhibition mechanism of social facilitation.

It is certain that an individual's drinking was in response to a water deficit imposed by $3 \mathrm{~h}$ of water deprivation and that it was susceptible to the social influence of other deprived companions. However, the position over sieving is less clearly stated. The motivational basis of sieving (see below) is not clear, nor is it certain why the deprived ducklings' sieving activity could not be facilitated by nondeprived companions. However, when a thirsty bird is presented with water, the sieving will continue long after drinking has finished and may thus represent a behavior pattern which lends itself more suitably to social facilitation when the reactor is allowed to complete the task before the actor(s) is introduced.

While the motivational aspects of sieving are not directly tackled by the present experiments they illustrate some of the problems involved and a few words on the subject appear appropriate. Sieving is 
essentially a feeding activity (Weidmann, 1956) which enables the bird to feed on small organic material without consuming vast quantities of water. It has been shown that early feeding movements of neonatal mammals are relatively independent of motivational factors associated with food deprivation. Thus, the neonatal kitten will continue to suck long after nutritional requirements have been met (Koepke \& Pribram, 1967). Comparable effects certainly occur in birds, where Hogan (1971) has shown that pecking in chicks at first shows little relationship to food deprivation. The fact that ducklings will sieve for long periods even when not food deprived (personal observation) argues in favor of similar effects occurring in ducklings.

The present experiment attempts to (a) demonstrate social facilitation of drinking and sieving behavior in water-deprived ducklings that have already begun to satiate their thirst, and (b) to see if this effect is susceptible to either the behavior or the number of the companions introduced. The introduction of deprived or nondeprived actors to a partially satiated duckling may possibly influence it to drink or sieve, respectively. The drinking and sieving may also increase as the number of companions is increased.

When isolated, socially reared ducklings show increased locomotion and distress calling which will have a disruptive effect on any ingestive behavior. This effect may even occur in four-bird flocks in which one or more members are absent, and to minimize this difficulty the present experiment introduced the remainder of the flock to a deprived companion after it had begun its drinking response. By using "flocks" of two, three, or four birds, it was possible to add one, two, or three companions to the single reactor bird.

\section{METHOD}

\begin{abstract}
Subjects
The experimental animals were 130 4-5-day-old Khaki Campbell ducklings. These are a domesticated form of Anas platyrhynchos and can be obtained commercially as day-olds throughout the year. On arrival, the ducklings were randomly divided into 40 flocks which consisted of 20 flocks of four birds, 10 of three birds, and 10 of two birds.
\end{abstract}

\footnotetext{
Apparatus

Husbandry and the experimental apparatus have been described in detail elsewhere (Clayton, 1976). Briefly, the flocks were housed in containers with ad-lib water and food (Purina Turkey Starter crumbs). The experimental apparatus consisted of a $76 \times 102 \mathrm{~cm}$ Perspex-sided arena within a larger hardboard and muslin-sided arena. As the only illumination in the experimental room was within the arena, the muslin walls provided an effective one-way screen. This arrangement permitted undisturbed observation of the birds from the side of the arena. A $12.8 \times 12.8 \times 3.2 \mathrm{~cm}$ water dish was placed along the midline in the half of the inner arena away from the startbox where they
}

were released. The arena's wire mesh floor was marked out in $12.8-\mathrm{cm}$ squares. The four squares which encompassed the water dish enabled the time spent by the birds in the vicinity of the water dish to be calculated.

\section{Procedure}

All birds were made familiar with the arena by releasing the nondeprived and undivided flocks into the arena for $15 \mathrm{~min}$ on both the 2 nd and 3 rd days before testing on the 4 th day.

The reactor animal was an arbitrarily selected duckling from each flock and was water deprived in isolation for $3 \mathrm{~h}$. A base line for the effects of the addition of the companions or actors was provided by the behavior of the reactor bird from 10 flocks of four birds. In this control situation, the flock companions were not introduced to the reactor bird which remained on its own for the whole 8-min test period. In the remaining 10 flocks of four birds, 10 of three birds, and 10 of two birds, the companions from half of the flocks (five from each flock size) were also water deprived at the same time as the reactor bird. The companions from the remaining 5 flocks of four, three, and two birds were not deprived. During the 3-h pretest period, all birds had access to food. At the end of this period, the reactor bird was released into the arena which contained water but not food. Four minutes later it was joined either by deprived (3D, 2D, or 1D, depending on the flock size) or by nondeprived (3C, 2C, 1C) companions. The test continued for a further $4 \mathrm{~min}$.

The behavior of all the ducklings was recorded on videotape and later transcribed onto a 12-channel event recorder when drinking, as recognized by the head-up posture, sieving (see above), and time spent near the water dish were reported. The analysis of variance and the trend analysis were the statistics used (Edwards, 1968), except where the data was not suitable (usually because of large numbers of zero scores), when nonparametric statistics (Siegel, 1956) were used.

\section{RESULTS}

Table 1 tabulates the mean total response for drinking, sieving, and time spent near the water dish by the single deprived reactor duckling under each condition for the first $4 \mathrm{~min}$ (Period I) and for the $4 \mathrm{~min}$ after the flock companions, the actors, had been added (Period II). The actors' behavior in Period II is also shown. These measures are graphically illustrated for the control situation $1 \mathrm{D} /$ - in the upper portion of Figure 1. Since the flock size failed to have any significant effects, the data has been amalgamated to produce the response of the reactor with nondeprived companions $(1 \mathrm{D} / 3 \mathrm{C}$, $1 \mathrm{D} / 2 \mathrm{C}, 1 \mathrm{D} / 1 \mathrm{C}$ ) in the middle portion of Figure 1 and that of the reactor with deprived companions $(1 \mathrm{D} / 3 \mathrm{D}, 1 \mathrm{D} / 2 \mathrm{D}, 1 \mathrm{D} / 1 \mathrm{D})$ in the lower portion of Figure 1.

\section{Period I}

The overall drinking of the reactor during Period I was not influenced by flock size $[F(2,24)=.106]$ and declined [trials effect, $F(3,72)=5.51, p<.01$ ] as the test proceeded. Sieving and time spent near the water dish remained at low levels throughout the period. 
Table 1

Overall Means for Drinking, Sieving, and Time Spent Near the Water Dish by the Reactor and Actor Birds Throughout the Experimental Period

\begin{tabular}{|c|c|c|c|c|c|c|c|c|c|}
\hline & \multirow[b]{2}{*}{ Flock Size } & \multicolumn{4}{|c|}{ Period I } & \multicolumn{4}{|c|}{ Period II } \\
\hline & & $\begin{array}{r}2 \\
1 / 1 \\
\end{array}$ & $\begin{array}{c}3 \\
1 / 2 \\
\end{array}$ & $\begin{array}{c}4 \\
1 / 3\end{array}$ & $\stackrel{4}{1 /-}$ & $\begin{array}{c}2 \\
1 / 1\end{array}$ & $\begin{array}{c}3 \\
1 / 2\end{array}$ & $\begin{array}{c}4 \\
1 / 3 \\
\end{array}$ & $\stackrel{4}{1 /-}$ \\
\hline Drink & $\begin{array}{l}\text { Deprived Reactor } \\
\text { Deprived Actors } \\
\text { Deprived Reactor } \\
\text { Nondeprived Actors }\end{array}$ & $\begin{array}{l}12.4 \\
10.2\end{array}$ & $\begin{array}{r}14.6 \\
8.2\end{array}$ & $\begin{array}{r}14.2 \\
8.2\end{array}$ & 13.9 & $\begin{array}{r}9.4 \\
26.2 \\
9.1 \\
2.4\end{array}$ & $\begin{array}{l}9.7 \\
24.8 \\
10.2 \\
1\end{array}$ & $\begin{array}{l}8 . \\
28.44 \\
10 . \\
1.47\end{array}$ & 5.9 \\
\hline Sieve & $\begin{array}{l}\text { Deprived Reactor } \\
\text { Deprived Actors } \\
\text { Deprived Reactor } \\
\text { Nondeprived Actors }\end{array}$ & $\begin{array}{l}2 \\
6.4\end{array}$ & $\begin{array}{l}0 \\
1\end{array}$ & $\begin{array}{l}3 \\
3.4\end{array}$ & 1.3 & $\begin{array}{l}43.6 \\
29.4 \\
33.2 \\
28.4\end{array}$ & $\begin{array}{l}36.8 \\
20.1 \\
32.2 \\
38.6\end{array}$ & $\begin{array}{l}34 \\
25 \\
29.6 \\
32.6\end{array}$ & 5.3 \\
\hline $\begin{array}{l}\text { Time } \\
\text { (\% of Total) }\end{array}$ & $\begin{array}{l}\text { Deprived Reactor } \\
\text { Deprived Actors } \\
\text { Deprived Reactor } \\
\text { Nondeprived Actors }\end{array}$ & $\begin{array}{l}54.5 \\
46\end{array}$ & $\begin{array}{l}36.6 \\
44.2\end{array}$ & $\begin{array}{l}43.4 \\
49.6\end{array}$ & 59.4 & $\begin{array}{l}76.9 \\
81.2 \\
68.45 \\
64.25\end{array}$ & $\begin{array}{l}67.7 \\
69.35 \\
57.5 \\
51.3\end{array}$ & $\begin{array}{l}69.2 \\
75.8 \\
59.8 \\
53.6\end{array}$ & 38.4 \\
\hline
\end{tabular}

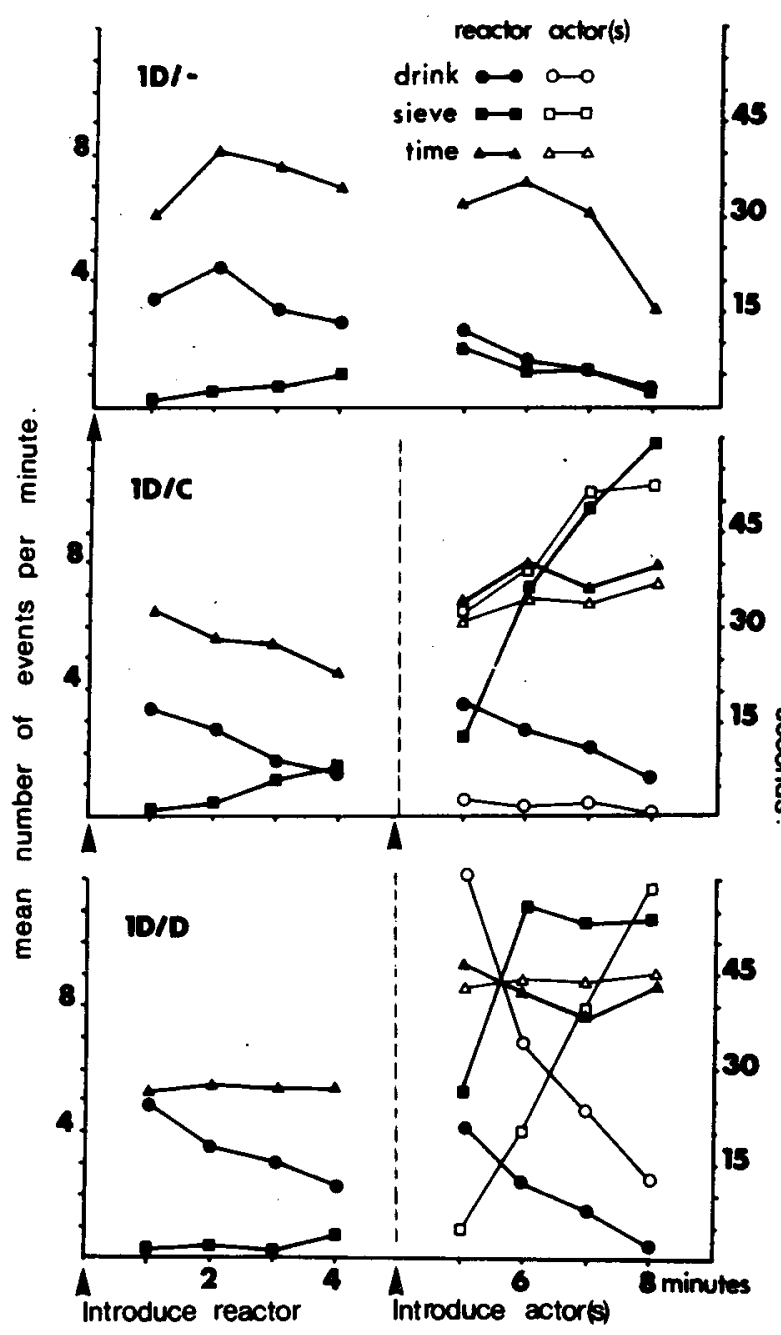

Figure 1. 1D/ - the control situation, the reactor without conspecifics; $1 \mathrm{D} / \mathrm{C}$, the reactor with nondeprived companions; and $1 \mathrm{D} / \mathrm{D}$, the reactor with deprived companions.

\section{Period II}

Actor's behavior. The deprived actors drank more (Mann-Whitney $\mathrm{U}, \mathrm{n}_{1}=30, \mathrm{n}_{2}=30 ; \mathrm{Z}=6.65$, $\mathrm{p}<.001)$ and sieved less $[\mathrm{F}(1,54)=4.46, \mathrm{p}<.05]$ than the deprived actors. A significant deprivation and trials interaction effect $[F(8,216)=2.18$, $\mathrm{p}<.05]$ showed that the nondeprived actors sieved more than the deprived actors when they were introduced. The deprived actors spent significantly more time $[F(1,54)=14.74, p<.005]$ near the water dish than did the nondeprived actors.

Reactor's behavior. The analysis of variance for drinking $[F(2,24)=.306]$ and sieving $[F(2,24)=1.51]$ of the reactor in Period II showed that the bird's response was not affected by whether or not the actors were deprived. The significant trials effects shows that drinking declined $[F(3,72)=25.07$, $\mathrm{p}<.001]$ while sieving increased $[\mathrm{F}(3,72)=19.33$, $\mathrm{p}<.001]$. The significant deprivation and trial interaction effect $[F(3,72)=2.47, p<.05]$ in the analysis of sieving showed that the reactor sieved more at the beginning of Period II when deprived, rather than when nondeprived, actors were introduced. While the reactors with deprived companions spent more time near the water dish than did those with nondeprived companions, it did not reach significance $[F(1,24)=2.18]$.

\section{Period I/Period II}

A comparison of the last minute of Period I with the first of Period II showed that both drinking [ $t$ test paired data, $t(14)=4.55, \mathrm{p}<.005$ ] and the sieving $[t(14)=3.58, p<.005]$ of the reactor increased significantly after the actors were added. The increase in drinking was not affected by the addition of deprived or nondeprived actors (MannWhitney $U=100.5, n_{1}=15, n_{2}=15$ ). The increase in sieving was greater when deprived rather 
than nondeprived actors were introduced $(U=60$, $\left.\mathrm{n}_{1}=15, \mathrm{n}_{2}=15, .025<\mathrm{p}<.05\right)$. The time spent near the water dish by the reactor increased after the companions were introduced, irrespective of whether they were deprived [t test paired data, $\mathrm{t}(14)=6.66, \mathrm{p}<.005]$ or nondeprived $[\mathrm{t}(14)=3.07$, $\mathrm{p}<.005]$. In comparison with the control reactor, the experimental reactor from the flocks of four birds sieved more $[\mathrm{t}(18)=5.35, \mathrm{p}<.005]$ and spent more time near the water dish $[\mathrm{t}(18)=2.31$, $\mathrm{p}<.025]$. Drinking increased when actors were added but not significantly over the whole period $[t(18)=1.68, p=.1]$.

\section{DISCUSSION}

When isolated, a socially reared duckling would wander about the arena distress calling. It might be expected that the reactor bird from larger flocks would be more affected by isolation than the isolate from the paired bird flocks, but an analysis of the time spent near the water dish showed that the flock size had no influence on this measure. The introduction of actors $4 \mathrm{~min}$ after the reactor had begun drinking led to an immediate increase in both the drinking and sieving behavior of that bird. This increase was not present when the bird remained on its own, as in the control (1D/-) situation. Using Peking ducks, Stettner and Tilds (1966) showed that the presence of an imprinted object had a similar effect on reducing distress calling and rapid pacing about in an open field (which in the present experiment is reflected in the low scores for time spent near the water dish during Period I). Hoffman, Stratton, and Newby (1969) have further shown that presentations of an imprinted stimulus could initiate feeding in Peking ducks with no prior pairing of the stimulus with food. Drinking was shown to occur at the same time, but it is apparent from their discussion and their method of recording (by using photocells on both the food and water trays) that this included sieving. Since the increase was produced by a stimulus unable to provide behaviorally directive cues, it is probable that the social facilitation effect they report was produced by the disinhibitory mechanism of social facilitation. This mechanism was also produced in the present experiment where the important factor in the immediate increase in drinking and sieving at the beginning of Period II was not the number of birds introduced or what they were doing, but rather that the introduction of companions restored the flock to its normal size.

The disinhibitory mechanism can also be illustrated by a consideration of the two bird flocks. In these flocks, the drinking and sieving of the actor in Period II was greater than that of the reactor in Period I.
However, disinhibition does not explain all the results, since a further increment in sieving behavior occurred when deprived, rather than nondeprived, actors were introduced. The failure to show a significant increase in the time spent near water by the partially satiated reactor birds with deprived companions means that it was unlikely that the increase in sieving was the result of spending more time at the water dish. Alternatively, the increase might have been caused by the deprived actors' drinking activity. Had the increase in the reactor birds' sieving been caused by the sieving activity of the actors, the facilitation would have been observed in the reactor birds' response to nondeprived companions where sieving was initially higher.

The failure to show nondisinhibitory facilitation of drinking was not surprising since this can only be obtained in deprived ducklings at the beginning of the drinking response. Another factor which may have disrupted any such facilitation was the pretest isolation of the birds (Clayton, 1976), and this may also account for the failure to show that the individual's drinking increased as the number of actors increased. As the reactor bird became satiated, drinking declined and the birds were no longer susceptible to facilitation of the drinking response by the deprived actors. However, sieving, an activity on the increase and which appears to be a selfperpetuating behavior inevitably and directly evoked by putting the bill in the water and independent of motivational control, in the sense that drinking was, became the response most likely to show facilitation to the same stimulus condition of a drinking companion.

This interpretation is consistent with the perceptual mechanism of social facilitation in which the social companion served to attract the attention of the reactor to the nonsocial stimulus, which elicited the facilitated response. The nonsocial stimulus, the water, would elicit drinking in a thirsty bird, but in the partially satiated duckling served only to elicit sieving.

\section{REFERENCES}

BAYER, E. Beitraege zur Zweikomponententheorie des Hungers. Zeitschrift für Psychologie, 1929, 112, 1-54.

BECK, G. Neue Beiträge zur Zweikomponententheorie des Hungers. Zeitschrift für Psychologie, 1931, 118, 283-349.

ClaYTON, D. A. Social interactions and the drinking behaviour of ducks. PhD thesis, Leicester University, 1972.

Clayton, D. A. The effect of pretest conditions on social facilitation of drinking in ducks. Animal Behaviour, 1976, 24, 125-134.

EDWARDs. A. L. Experimental design in psychological research. New York: Holt, Rinehart, \& Winston, 1968.

Hoffman, H. S., Stratton, J. W., \& Newby, V. The control of feeding behavior by an imprinted stimulus. Journal of Experimental A nimal Behavior, 1969, 12, 847-860. 
Hogan, J. A. The development of a hunger system in young chicks. Behaviour, 1971, 39. 128.201.

Koepke, J. E., \& Pribram, K. H. Effects of food reward on the maintenance of sucking behaviour during infancy. Proceedings of the 75th Annual Convention of the American Psychological Association, 1967, 111-112.

MAY, J. G., \& DoRR. D. Imitative pecking in chicks as a function of early social experience. Psychonomic Science, 1968, 11, 175.

Platt. J. J., \& James, W. T. Social facilitation of eating behaviour in young oppossums. I: Grouped versus solitary feeding. Psychonomic Science, 1966, 6, 421-422.

Ross, S., \& Ross, J. G. Social facilitation of feeding in dogs. II: Feeding after satiation. Journal of Genetic Psychology, 1949, 74, 293-304.

SIEGEL, S. Non-parametric statistics for the behavioral sciences. New York: McGraw-Hill, 1956.

Simmel, E. C. Social facilitation of exploratory behaviour in rats. Journal of Comparative and Physiological Psychology, 1962, 55, 831-833.

Stettner, L. J., \& Tilds, B. N. Effect of presence of an imprinted object on response of ducklings in an open field and when exposed to a fear stimulus. Psychonomic Science, 1966, 4, 107-108.
Tolman, C. W. Social facilitation of feeding behaviour in the domestic chick. Animal Behaviour, 1964, 12, 245-251.

Tolman, $C$. W. The role of the companion in social facilitation of animal behaviour. In E. C. Simmel, R. A. Hoppe, \& G. A. Milton (Eds.), Social facilitation and imitative behaviour. Boston: Allyn \& Bacon, 1968.

Tolman, C. W. Social feeding in domestic chicks: Effects of food deprivation of non-feeding companions. Psychonomic Science, $1969,15,234$.

TURNER, E. R. A. Social feeding in birds. Behaviour, 1964, 24, $1-46$.

WeIDMann, U. Verhaltensstudien au der Stockente (Anas platyrhynchos L.) I: Das Aktionsystem. Zeitschrift für Tierpsychologie, 1956, 13, 208-271.

Wilson, $\bar{G}$. F. Early experience and facilitation of feeding in domestic chicks. Journal of Comparative and Physiological Psychology, 1968, 66, 800-802.

ZAJonc, R. B. Social facilitation. Science, 1965, 149, 269-274.

(Received for publication January 10, 1975; revision accepted May 27, 1976.) 